\title{
A phase I trial of the trifunctional anti Her $2 \times$ anti CD3 antibody ertumaxomab in patients with advanced solid tumors
}

\author{
N. Haense ${ }^{1 \dagger}$, A. Atmaca ${ }^{2 \dagger}$, C. Pauligk' , K. Steinmetz ${ }^{1}$, F. Marmé ${ }^{3}$, G. M. Haag ${ }^{3}$, M. Rieger ${ }^{4}$, O. G. Ottmann ${ }^{5}$, P. Ruf ${ }^{6}$, \\ H. Lindhofer ${ }^{6}$ and S.-E. Al-Batran ${ }^{1 *}$
}

\begin{abstract}
Background: Ertumaxomab (ertu) is a bispecific, trifunctional antibody targeting Her2/neu, CD3 and the Fcy-receptors I, Ila, and III forming a tri-cell complex between tumor cell, T cell and accessory cells.

Methods: Patients (pts) with Her2/neu (1+/SISH positive, 2+ and 3+) expressing tumors progressing after standard therapy were treated to investigate safety, tolerability and preliminary efficacy. In this study, ertu was applied i.v. in 2 cycles following a predefined dose escalating scheme. Each cycle consisted of five ascending doses (10-500 $\mathrm{\mu g}$ ) applied weekly within 28 days with a 21 day treatment-free interval. If 2 pts experienced a dose limiting toxicity (DLT) at a given dose level, the maximum tolerated dose (MTD) had been exceeded.

Results: Fourteen heavily pretreated pts (e.g. breast, rectal, gastric cancer) were enrolled in the four main cohorts. Three (21\%) pts had to be replaced. Two serious adverse events (SAE) with possible relation to the investigational drug were seen, both fully reversible. A DLT was not detected. Consequently, the MTD could not be determined. All adverse events (AE) were transient and completely reversible. Most frequent AEs were fatigue (14/14), pain (13/14), cephalgia (12/14), chills (11/14), nausea (8/14), fever (7/14), emesis (7/14) and diarrhea (5/14). Single doses up to $300 \mu \mathrm{g}$ were well tolerated (total dose up to $800 \mathrm{\mu g}$ per cycle). We observed one partial remission and two disease stabilizations after first treatment cycle.
\end{abstract}

Conclusions: Single doses up to $300 \mu \mathrm{g}$ could be safely administered in an escalating dose scheme. Immunological responses and clinical activity warrant further evaluation in patients with Her2 over expressing tumors.

Trial registration: EudraCT number: 2011-003201-14; ClinicalTrials.gov identifier: NCT01569412

Keywords: Ertumaxomab, Her2/neu, Advanced cancer, Dose limiting toxicity, Dose escalation, Maximum tolerated dose

\section{Background}

The most known member of the epidermal growth receptor family, Her2/neu, is frequently found to be overexpressed in various types of cancers like breast cancer, gastric cancer, lung cancer and ovarian cancer. An increased Her2/neu expression results in a more aggressive tumor behavior. Thus, many studies have indicated that Her2/neu overexpression is associated with a poor prognosis and with a significantly shorter overall survival

\footnotetext{
* Correspondence: albatran.salah@khnw.de

${ }^{\dagger}$ Equal contributors

'Institute of clinical research (IKF) at Krankenhaus Nordwest, UCT-University Cancer Center, Steinbacher Hohl 2-26, 60488 Frankfurt am Main, Germany

Full list of author information is available at the end of the article
}

rate and time to relapse for patients with Her2/neu expressing tumors $[1-3]$.

The Her2/neu (c-ErbB-2) proto-oncogene encodes an $185 \mathrm{kD}$ trans-membrane glycoprotein that takes action as a tyrosine kinase receptor [3]. As a tyrosine kinase receptor, Her2/neu participates in an interactive network of receptor interactions resulting in complex signaling pathways to control and regulate cell growth, migration, differentiation and death [3-5].

An overexpression of Her2/neu, often caused by amplification of the c-ErbB-2 gene, leads to enhanced tyrosine phosphorylation activity and therefore to increased cell proliferation and metastatic transformation in tumors $[5,6]$. 
Thus, the Her2/neu receptor serves as an effective target for antineoplastic agents [6].

Bispecific antibodies are a new and promising approach for immunologic treatment of cancer cells. Therefore, a simultaneous and powerful activation of effector cells such as T cells, NK cells and dendritic cells is preferable. However, the bispecific antibodies generated so far normally activate only a single class of effector cells resulting in an insufficient immunologic attack against tumor cells [7]. Triomab ${ }^{\bullet}$ antibodies represent a new class of bispecific, hybrid-hybridoma derived antibodies configured of two potent subclasses of mouse IgG2a and a rat IgG2b chain. As a welcoming result of this structure, triomab ${ }^{\circledR}$ antibodies possess three different binding sides: a tumor-associated antigen (TAA)-specific binding arm, a second arm specific for CD3 expressed on $\mathrm{T}$ cells, and a chimeric mouse IgG2a $\mathrm{x}$ rat IgG2b Fc region that recognizes $F_{C} \gamma$ receptors type I, IIa and III present on accessory cells such as macrophages, dendritic cells or NK cells [8-10].

Here, we report data on a new immunotherapeutic agent, ertumaxomab (ATC code L01XC). Ertumaxomab is a bispecific, trifunctional antibody that binds to Her2/ neu as its tumor-associated antigen, to CD3 and to Fcy forming a tri-cell complex between tumor cell, $\mathrm{T}$ cell and accessory cells (Fig. 1). As a result, various immunologic mechanisms are induced to initiate a polyclonal humoral and cellular immune response to destroy Her2/ neu expressing tumor cells:

a) Mediation of $\mathrm{T}$ cell activation by $\mathrm{CD} 3$ binding results in tumor cell killing by e.g. cytokine release and release of lytic enzymes such as perforins $[7,11]$. b) T cells receive a second activating signal by release of stimulating cytokines (e.g. IL-2) and a crosstalk between costimulatory molecules now expressed on $\mathrm{T}$ cells and accessory cells [7, 12]. c) Necrotic or apoptotic tumor particles are phagocytized by Fcy positive cells such as macrophages resulting in uptake, processing and presentation of these tumor particles. Consequently, an antitumor immunization against Her2/neu and other unknown tumor-associated antigens is induced resulting in the generation of cytotoxic T-cells and tumor-specific antibody producing plasma cells. Finally, the mode of action of triomab ${ }^{\oplus}$ antibodies, e.g. ertumaxomab, develops a protective longterm anti-tumor immunity $[9,13,14]$.

This effective attack of various immunologic cells activating complex immunologic mechanisms leads to significant tumor cell elimination. Heiss et al. demonstrated that patients with malignant ascites gain a clear clinical benefit when treated i.p. with the trifunctional anti-EpCAM $\mathrm{x}$ anti-CD3 antibody catumaxomab [15].

Recently, Kiewe et al. published promising data for the trifunctional anti-Her2/neu $\mathrm{x}$ anti-CD3 antibody ertumaxomab. In a phase I trial patients with metastatic breast cancer were enrolled and treated with the trifunctional antibody in a dose escalating scheme. A clinical response to ertumaxomab treatment was seen in five out of fifteen patients [12]. These results are encouraging and indicate antitumor efficacy. Also, the finding that ertumaxomab has a different mode of action compared with trastuzumab, a monoclonal anti-Her2/neu antibody [16], strengthened the idea of investigating this triomab ${ }^{\odot}$ antibody in a second phase I study enrolling patients with Her $2 /$ neu (IHC 1+/ISH positive, 2+, 3+) expressing solid tumors.

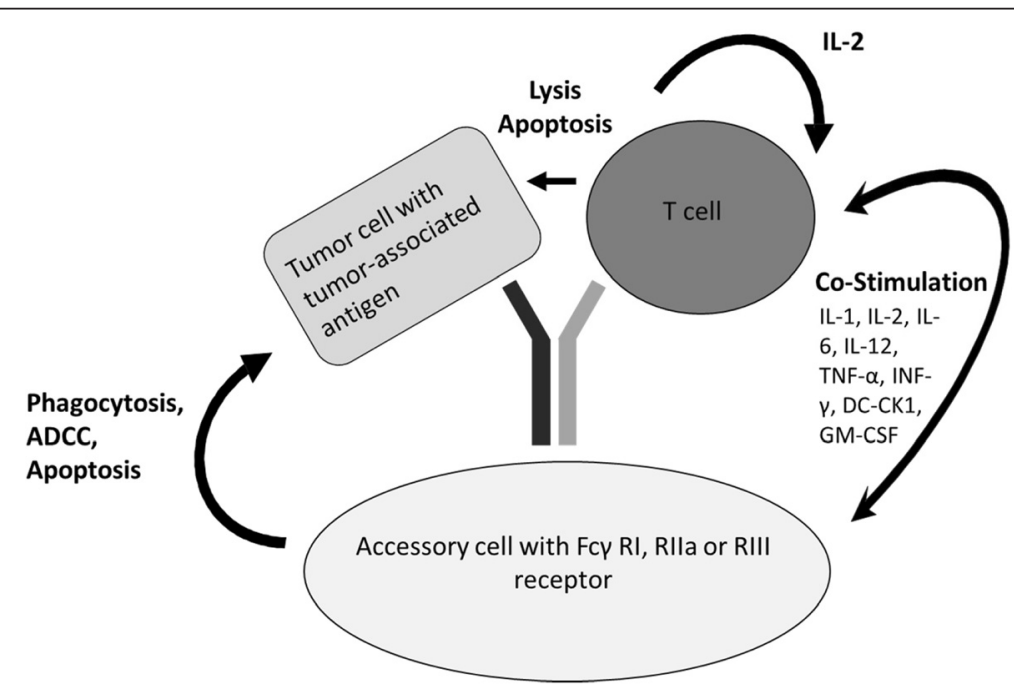

Fig. 1 Mode of action of a triomab antibody. The trifunctional antibody unites tumor cell, T cell and accessory cells to form a tri-cell complex to induce tumor cell destruction and phagocytosis. Abbreviations: ADCC, antibody dependent cellular cytotoxicity; DC, dendritic cell; DC-CK1, dendritic cell cytokine 1; IL, interleukin; LFA, leukocyte function associated antigen; NK, natural killer cell; TNF-a, tumor necrosis factor alpha; INF- $\gamma$, interferon gamma; GM-CSF, granulocyte macrophage colony-stimulating factor. Modified ${ }^{10,12}$ 
A phase I trial was designed to investigate the safety, tolerability and preliminary efficacy of ertumaxomab in patients with solid tumors progressing after standard therapy. In order to increase the amount of applied doses and to reduce toxicity compared to a previous study in breast cancer [12], we used a modified dosing schedule with small dose escalation steps and five consecutive, weekly administrations.

\section{Methods}

\section{Study design}

The primary objective in this single center phase I trial was the evaluation of safety and tolerability of the trifunctional antibody ertumaxomab in patients with Her2/ neu expressing solid tumors in order to determine the maximum tolerated dose (MTD) and to establish a recommended dose (RD) for further investigations. Secondary endpoints were antitumor activity (disease control rate) and the measurement of immunological response (anti-drug antibodies [HAMA], humoral immune responses [Anti-EpCam- and anti-Her2/neu antibodies], lymphocyte cell count).

The study (EudraCT number: 2011-003201-14; ClinicalTrials.gov identifier: NCT01569412) was conducted according to the principles of the International Conference of Harmonization-Good Clinical Practice and approved by the institutional ethics committee. All relevant authorities were notified according to German drug law.

\section{Patient eligibility}

Patients were eligible if they had histologically confirmed solid Her2/neu positive ( $1+/$ ISH positive, $2+$ and $3+$ ) tumors, no available standard treatment, measurable disease according to RECIST 1.1., disease progression during or after standard therapy, age $>18$ years, ECOG performance status $0-2$, adequate hematological, liver, kidney and cardiac function (LVEF $>50 \%$ ). Unlike common criteria for anti-Her2/neu strategies, patients with score $2+$ were eligible regardless of their ISH results, as "immunotherapy effects" were expected also in patients with moderate Her2/neu overexpression.

Patients were excluded if they had known hypersensitivity to murine proteins or other components of the drug, any concurrent chemotherapy, radiotherapy, hormone therapy, immunotherapy or treatment with any investigational drug within 2 weeks prior to study entry, a documented autoimmune disease, HIV, HBV, HCV, acute or chronic infections or other concurrent nonmalignant co-morbidities, $\geq 5$ preceding chemotherapy lines (to exclude potentially immunocompromised patients), prior diagnosis of any other uncured malignancy, any documented evidence of symptomatic brain or central nervous system metastases or abnormal organ or bone marrow function.
All patients signed an informed consent form before participating in the trial.

\section{Treatment plan and dose escalation}

In this investigator driven, open label, uncontrolled trial the administration of ertumaxomab followed a predefined dose escalation scheme (Table 1) consisting of two doseidentical cycles with five ascending doses $(10 \mu \mathrm{g}$ to $500 \mu \mathrm{g})$ per cycle. In order to avoid cytokine release related symptoms associated with application of higher doses in treatment naïve patients, an intraindividual dose escalating schedule in each cohort was chosen, starting with low doses. Patients were treated once weekly from day 1 to 28 (i.e. one cycle) followed by a treatment-free interval of 21 days in-between (Fig. 2). The dose escalation into the next dose level occurred when three patients had received all five administrations of the first cycle without experiencing a dose limiting toxicity (DLT). If one patient had shown a DLT, additional three patients had to be enrolled and treated at the same dose level before proceeding into next dose level. If a DLT was seen in two patients at a given dose level, the MTD had been exceeded. Dose levels 1, 5, 9 and 13 were the main cohorts (in bold letters). The intermediate cohorts served to identify the MTD if $\geq 2$ DLTs occurred in a main cohort (Table 1).

\section{Drug administration}

Ertumaxomab was manufactured by TRION Pharma $\mathrm{GmbH}$, Munich, under good manufacturing practice conditions and approved by the local authority. The

Table 1 Dose escalation scheme

\begin{tabular}{lll}
\hline Dose level & Escalation scheme $[\mu \mathrm{g}]$ & No. of pts \\
\hline $\mathbf{1}^{\mathbf{a}}$ & $\mathbf{1 0 - 5 0 - 1 0 0 - 1 0 0 - 1 0 0}$ & $\mathbf{3}-\mathbf{6}$ \\
2 & $10-50-100-100-150$ & $3-6$ \\
3 & $10-50-100-150-150$ & $3-6$ \\
4 & $20-50-100-150-150$ & $3-6$ \\
$\mathbf{5}^{\mathbf{a}}$ & $\mathbf{2 0 - 5 0 - 1 0 0 - 1 5 0 - 2 0 0}$ & $\mathbf{3}-\mathbf{6}$ \\
$\mathbf{6}$ & $20-50-100-150-250$ & $3-6$ \\
7 & $20-50-100-200-200$ & $3-6$ \\
8 & $50-100-150-200-200$ & $3-6$ \\
$\mathbf{9}^{\mathbf{a}}$ & $\mathbf{2 0 - 5 0 - 1 0 0 - 2 0 0 - 3 0 0}$ & $\mathbf{3}-\mathbf{6}$ \\
10 & $20-50-100-200-350$ & $3-6$ \\
11 & $50-100-100-150-200$ & $3-6$ \\
12 & $50-100-150-200-200$ & $3-6$ \\
$\mathbf{1 3}$ & $\mathbf{5 0 - 1 0 0 - 1 5 0 - 2 0 0 - 3 0 0}$ & $\mathbf{3 - 6}$ \\
14 & $50-100-150-300-300$ & $3-6$ \\
15 & $50-150-150-300-300$ & $3-6$ \\
16 & $50-150-300-400-500$ & $3-6$ \\
\hline
\end{tabular}

Abbreviations: Pts patients

${ }^{\text {a }}$ Main cohort 


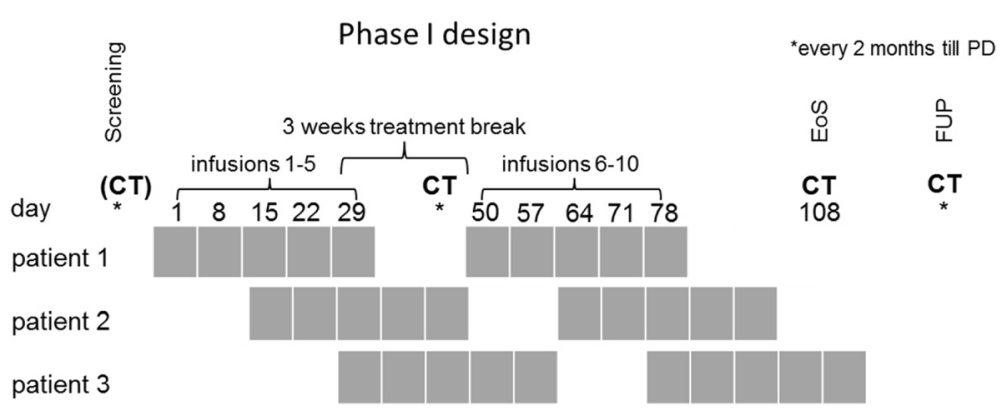

Fig. 2 Study design. Abbreviations: CT, computed tomography; PD, progressive disease; EoS, End of Study; FUP, follow up

antibody was supplied by TRION Pharma as a sterile, clear, colorless, preservative-free concentrate in prefilled syringes. The syringes contained $10 \mu \mathrm{g}$ or $50 \mu \mathrm{g}$ of antibody and had to be dissolved in $0.9 \%$ sodium chloride solution to a total volume of $10 \mathrm{ml}$ or $50 \mathrm{ml}$. Ertumaxomab was administered as an i.v. infusion with a constant rate over $3 \mathrm{~h}$. Afterwards, $600 \mathrm{mg}$ of Ibuprofen were given orally to allay possible side effects of the immunologic therapy. Patients remained under hospital care and surveillance for $24 \mathrm{~h}$ after start of the infusion.

\section{Toxicity assessment}

Adverse Events (AE) were assessed at every visit by clinical examination and laboratory tests and graded according to the National Cancer Institute Common Toxicity Criteria (CTC), version 4.0. Respectively, patients were monitored frequently during their stay at the hospital and at the scheduled follow-up visits: medical examinations including vital signs, general physical examinations, electrocardiography and echocardiography were performed for safety before or during drug administration. Laboratory safety parameters including blood chemistry and hematology were measured before and $24 \mathrm{~h}$ after every infusion.

DLTs were predefined in the study protocol as any grade $\geq 3$ drug related non-hematological toxicity except events that were not optimally treated with standard medication $>3$ days of duration, any irreversible grade $\geq 3$ infusion-related reaction (defined as allergic reaction, fever, pain, bronchospasm, wheezing or hypoxia, occurring during or within $24 \mathrm{~h}$ after completing an infusion and resolving with a reduced infusion rate, supportive care and/or the administration of corticosteroids); any grade $\geq 3$ elevation of liver enzymes that was not declining within 7 days after drug administration; any grade $\geq 4$ toxicity, which have not been mentioned above as well as any grade $\geq 3$ event considered to be a DLT by the investigator. Moreover, fatigue (CTC grade $\geq 3$ ) lasting less than 14 days and isolated laboratory abnormalities grade $\geq 3$ that resolved to baseline or CTC grade 2 within 7 days without clinical sequelae or need for therapeutic intervention were not considered as a DLT.

\section{Efficacy measurement}

Tumor assessments according to response evaluation criteria in solid tumors (RECIST) were planned for the screening, the treatment-free interval before the second cycle (day 42-49) and for the end of study (day 108) as well as for follow up visits.

\section{Immunological analyses}

As ertumaxomab is an antibody derived from mouse and rat IgG, it has the potential of immunogenicity when administered to humans. Thus, patient plasma samples for the determination of human anti-murine antibodies (HAMAs) were collected before the first cycle, before the second cycle and at the end of study. Testing for HAMAs was performed using the Medac test (Medac, Hamburg).

Also, humoral immune responses against tumorassociated antigens e.g. anti-EpCam- and anti-Her2/neu antibodies were measured during the treatment. For the detection of anti-EpCam antibodies, a bridging ELISA format was applied, anti-Her2 antibodies were measured by immobilization of recombinant Her2 (Bender Med Systems) to the plate surface and using Herceptin as a calibrator. These assays provided information about potential vaccination effects against various tumor-associated antigens evolving during ertumaxomab treatment.

Lymphocyte subsets were analyzed from peripheral blood samples obtained before each infusion and $24 \mathrm{~h}$ after each infusion. Percentage and absolute counts of the different lymphocyte populations were determined using the Becton Dickinson (BD) Multitest IMK kit.

\section{Statistics}

This study was exploratory and not powered to address any pre-defined hypotheses. The safety and efficacy analysis was performed on every patient who received at least one infusion of ertumaxomab. Also, safety and efficacy were analyzed by appropriate descriptive statistics. All other endpoints were summarized descriptively. 


\section{Results}

\section{Patient characteristics}

Out of 14 enrolled patients, three patients received only two administrations of the investigational antibody ertumaxomab and had to be replaced. Reasons for discontinuing the trial were allergic reaction, death and liver failure all classified as non DLT (e.g. disease related). Therefore, eleven patients were treated with ertumaxomab according to protocol. They all completed the first cycle, three of them continued with the second cycle. The patient characteristics are outlined in detail in Table 2.

\section{Dose escalation}

Fourteen patients were enrolled in four main cohorts with different dose levels: cohort 1 (10-50-100-100-100 $\mu \mathrm{g}$ ), three patients; cohort 5 (20-50-100-150-200 $\mu \mathrm{g})$, four patients; cohort 9 (20-50-100-200-300 $\mu \mathrm{g})$, three patients; cohort 13 (50-100-150-200-300 $\mu \mathrm{g})$; four patients. In this dose escalation scheme, single doses up to $300 \mu \mathrm{g}$ were well tolerated. The received doses ranged from $10 \mu \mathrm{g}$ to $300 \mu \mathrm{g}$ as a single application and from $360 \mu \mathrm{g}$ to $800 \mu \mathrm{g}$

Table 2 Patient characteristics

\begin{tabular}{|c|c|}
\hline Patient characteristics & $\begin{array}{l}\text { No. of patients (\%) } \\
n=14\end{array}$ \\
\hline $\begin{array}{l}\text { Sex } \\
\text { Male } \\
\text { Female }\end{array}$ & $\begin{array}{l}4(28.6) \\
10(71.4)\end{array}$ \\
\hline $\begin{array}{l}\text { Age } \\
\text { Median age, years (range) }\end{array}$ & $54,5(35-72)$ \\
\hline $\begin{array}{l}\text { ECOG performance status } \\
\text { O } \\
1 \\
2\end{array}$ & $\begin{array}{l}8(57.1) \\
5(35.7) \\
1(7.1)\end{array}$ \\
\hline $\begin{array}{l}\text { Primary tumor location } \\
\text { Breast } \\
\text { Rectum } \\
\text { Stomach } \\
\text { Others }^{a}\end{array}$ & $\begin{array}{l}5(35.7) \\
3(21.4) \\
3(21.4) \\
3(21.4)\end{array}$ \\
\hline $\begin{array}{l}\text { No. of organs involved (primary excluded) } \\
1 \\
2 \\
3 \\
\geq 4\end{array}$ & $\begin{array}{l}5(35.7) \\
3(21.4) \\
2(14.3) \\
4(28.6)\end{array}$ \\
\hline $\begin{array}{l}\text { Organs involved (primary tumor excluded) } \\
\text { Lymph nodes } \\
\text { Lung } \\
\text { Liver } \\
\text { Abdominal Wall } \\
\text { Bone } \\
\text { Others }{ }^{b}\end{array}$ & $\begin{array}{l}7(50.0) \\
5(35.7) \\
3(21.4) \\
3(21.4) \\
3(21.4) \\
10(71.4)\end{array}$ \\
\hline $\begin{array}{l}\text { Her2 status } \\
\qquad \begin{array}{l}\text { IHC } 2+/ \mathrm{ISH}+ \\
\text { IHC } 3+\end{array}\end{array}$ & $\begin{array}{l}3(21.4) \\
11(78.6)\end{array}$ \\
\hline
\end{tabular}

Abbreviations: ECOG Eastern Cooperative Oncology Group, IHC immunohistochemistry, ISH in-situ hybridisation

a Others: head and neck (2 pts), pancreas (1 pt)

bOthers: adrenal gland, spleen, bladder, lymphangiosis carcinomatosa, pleura, peritoneum, chest wall, brain, skin in total per cycle. The dose escalation proceeded into the 13th dose level (50-100-150-200-300 $\mu \mathrm{g}$ ) without showing a DLT. Consequently, in this scheme the MTD is not reached and a RD not found so far.

\section{Safety}

Out of all serious adverse events (SAEs) that occurred during the trial $(n=12)$, only two were possibly or certainly related to the administration of the investigated antibody ertumaxomab and thus classified as SAR (serious adverse reaction): one patient (\#5) experienced an allergic reaction after the second application $(50 \mu \mathrm{g})$. Her main symptom was dyspnea with pain in the upper abdomen. The other SAR emerged in patient \#14 after his second infusion with $100 \mu \mathrm{g}$ of ertumaxomab. He developed a fever (CTC grade 1) which was accompanied by other symptoms as chills, abdominal pain, nausea and vomiting leading to unplanned hospitalization. Both SARs were fully reversible.

All patients showed treatment-related toxicities. Most frequent adverse events (AEs) were fatigue (14/14 patients, $100 \%)$, (tumor-) pain (13/14 patients, $93 \%)$, cephalgia (12/14 patients, $86 \%)$, chills (11/14 patients, $79 \%)$, nausea (8/14 patients, $62 \%)$, fever (7/14 patients, $50 \%)$, emesis (7/14 patients, $50 \%)$ and diarrhea (5/14 patients, $43 \%)$. All AEs were mild and completely reversible. An infusion with paracetamol ended or eased the symptoms during the ertumaxomab administration immediately. There was no cardiotoxicity revealed by monitoring of the clinical heart function during treatment with ertumaxomab. All treatment-related adverse events that occurred in the total population are listed in detail in Table 3.

\section{Efficacy}

Three out of eleven patients evaluable for response showed disease stabilization or partial response after the first cycle of ertumaxomab (day 42-49): A partial response was seen in patient \#6 (metastatic breast cancer) with a regression of hepatic metastases at first tumor evaluation. At the end of study, a progression in her axillary and hilar lymph nodes could be observed, but liver metastases were still in regress. Two patients (\#1- rectal cancer and \#2-head and neck cancer) were stable after the first cycle of ertumaxomab. They also had a progressive disease at end of study. There was no difference between tumor assessments according to RECIST. All three patients had Her2 IHC score 3+ tumors, two patients with disease stabilization were treated in dose level 1 , one patient with partial response in dose level 5. Selected characteristics of disease together with an overall response of all patients treated with ertumaxomab are provided in Table 4. 
Table 3 Adverse events (AEs) with possible relationship to ertumaxomab treatment (Adverse Drug Reaction) graded according to CTC AE (version 4.0)

\begin{tabular}{|c|c|c|c|c|c|c|c|c|c|}
\hline \multirow[b]{4}{*}{ AES } & \multirow{3}{*}{\multicolumn{2}{|c|}{$\begin{array}{l}\text { Dose level } 1 \\
(n=3) \\
n\end{array}$}} & \multirow{3}{*}{\multicolumn{2}{|c|}{$\begin{array}{l}\text { Dose level } 5 \\
(n=4) \\
n\end{array}$}} & \multirow{3}{*}{\multicolumn{2}{|c|}{$\begin{array}{l}\text { Dose level } 9 \\
(n=3) \\
n\end{array}$}} & \multirow{3}{*}{\multicolumn{2}{|c|}{$\begin{array}{l}\text { Dose level } 13 \\
(n=4) \\
n\end{array}$}} & \multirow{4}{*}{$\begin{array}{l}\sum \\
\text { AEs } \\
(n=14) \\
n[\%] \\
\Sigma\end{array}$} \\
\hline & & & & & & & & & \\
\hline & & & & & & & & & \\
\hline & $G 1 / G 2$ & G3 & G1/G2 & G3 & G1/G2 & G3 & $G 1 / G 2$ & G3 & \\
\hline Fatigue & 2 & 1 & 1 & 3 & 2 & 1 & 3 & 1 & $14(100,0)$ \\
\hline Cephalgia & 2 & - & 3 & - & 3 & - & 4 & - & $12(85,7)$ \\
\hline Chills & 3 & - & 2 & - & 3 & - & 3 & - & $11(78,6)$ \\
\hline Nausea & 1 & - & 2 & - & 2 & - & 3 & - & $8(61,5)$ \\
\hline Emesis & 1 & - & 2 & - & 2 & - & 2 & - & $7(50,0)$ \\
\hline Fever & 1 & - & 2 & 1 & 2 & - & 1 & 1 & $7(50,0)$ \\
\hline Hypertension & 3 & - & 2 & - & 1 & - & 1 & - & $7(50,0)$ \\
\hline Tumorpain & - & - & 1 & 2 & 2 & - & 1 & 1 & $7(50,0)$ \\
\hline Pain $^{a}$ & 1 & - & 4 & - & 1 & - & - & - & $6(42,9)$ \\
\hline Diarrhea & 1 & - & 2 & - & 1 & - & 1 & - & $5(42,9)$ \\
\hline Pain in the limbs & - & - & 2 & - & - & - & 3 & - & $5(42,9)$ \\
\hline$\uparrow C R P$ & 1 & - & 1 & - & 1 & - & 1 & - & $4(28,6)$ \\
\hline Tachycardia & 1 & - & 1 & - & 2 & - & - & - & $4(28,6)$ \\
\hline$\uparrow G G T$ & - & - & 2 & - & 1 & - & - & - & $3(21,4)$ \\
\hline$\uparrow A L T / A S T$ & - & - & 1 & - & 1 & - & - & - & $2(14,3)$ \\
\hline$\downarrow$ Lymphocytes & - & - & 2 & - & - & - & - & - & $2(14,3)$ \\
\hline Agitation & - & - & 1 & - & - & - & 1 & - & $2(14,3)$ \\
\hline Dermatitis & - & - & 2 & - & - & - & - & - & $2(14,3)$ \\
\hline Hypotension & 1 & - & - & - & 1 & - & - & - & $2(14,3)$ \\
\hline Dizziness & - & - & - & - & 1 & - & 1 & - & $2(14,3)$ \\
\hline Sensorium & - & - & 2 & - & - & - & - & - & $2(14,3$ \\
\hline Allergic reaction ${ }^{b}$ & - & - & 1 & - & - & - & - & - & $1(7,1)$ \\
\hline
\end{tabular}

Per patient every AE was counted once with its highest CTC grade. Only AE occurring in $>1 \mathrm{pt}$ are listed (exception: allergic reaction)

Abbreviations: $G$ grade according to CTC criteria, CRP C-reactive protein, ALT/AST aspartate aminotransferase/alanine aminotransferase, GGT gamma-glutamyl transpeptidase

aPain: not further specified

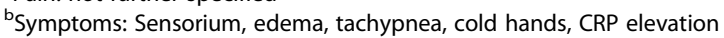

\section{Immunologic parameters}

All patients showed a decrease of their CD3+ T cell count $24 \mathrm{~h}$ after receiving the investigational drug. One week later, their CD3+ lymphocyte count had normalized to baseline values. The decrease was dose dependent. Thus, the transient lymphocytopenia was more pronounced in higher levels of dose. The median distribution of the CD3+ T cell count of all patients is plotted in Fig. 3.

One out of five evaluable patients evolved antiEpCam antibodies during the trial. The other four of these five patients had already preexistent anti-EpCam antibodies. The levels were in the range of 219$546 \mathrm{ng} / \mathrm{ml}$ and did not change significantly during treatment. Also, at end of study, anti-Her/neu antibodies were found in three out of five patients, all without pre-existing anti Her2/neu antibodies. Figure 4 shows a representative of a typical humoral immune response with corresponding, increasing levels for anti Her2/neu and anti-EpCam antibodies, which was seen in patient \#4.

The analysis for HAMAs at screening showed that all tested patients were negative for HAMAs, whereas eight out of nine evaluable patients were found to be HAMApositive at the end of study. There was no dose dependency seen for the development of HAMAs neither was a correlation to a different toxicity profile detected.

\section{Discussion}

In this phase I trial we could show that treatment with ertumaxomab in a slow weekly escalating dosing regimen for five consecutive applications is feasible. 
Table 4 Corresponding study data and clinical charcteristics of patients

\begin{tabular}{|c|c|c|c|c|c|c|c|c|c|}
\hline No. & Age range & Tumor & ECOG PS & No. of prior $\mathrm{CHT}$ & Organs involved & Her2 Status ${ }^{1}$ & Dose level & No. of cycles & Best response \\
\hline 01 & $70-80$ & Rectum & 1 & 4 & LN, PUL, HEP, ADR & $\mathrm{IHC} 3+$ & 1 & 2 & SD \\
\hline 02 & $70-80$ & Head and neck & 1 & 3 & LN, PUL & $\mathrm{IHC} 3+$ & 1 & 2 & SD \\
\hline 03 & $40-50$ & Rectum & 0 & 3 & $\begin{array}{l}\text { LN, SPLEEN, BLADDER, } \\
\text { ABDOM WALL }\end{array}$ & $\mathrm{IHC} 3+$ & 1 & 1 & PD \\
\hline 04 & $60-70$ & Pancreas & 1 & 3 & ABDOM WALL & $\mathrm{IHC} 2+, \mathrm{ISH}+$ & 5 & 1 & PD \\
\hline 05 & $50-60$ & Breast & 0 & 4 & PUL, OSS, LYMPHANG & $\mathrm{IHC} 3+$ & 5 & 0 & ND \\
\hline 06 & $50-60$ & Breast & 0 & 3 & HEP & IHC 3+ & 5 & 2 & $P R$ \\
\hline 07 & $50-60$ & Rectum & 1 & 3 & $\begin{array}{l}\text { LN, PUL, PLEU, } \\
\text { ABDOM WALL, PERI }\end{array}$ & $\mathrm{IHC} 2+, \mathrm{ISH}+$ & 5 & 1 & PD \\
\hline 08 & $40-50$ & Stomach & 0 & 4 & $\mathrm{LN}$ & $\mathrm{IHC} 3+$ & 9 & 1 & PD \\
\hline 09 & $50-60$ & Breast & 0 & 3 & $\begin{array}{l}\text { CHEST WALL, } \\
\text { CEREB, HEP, OSS }\end{array}$ & $\mathrm{IHC} 3+$ & 9 & 1 & PD \\
\hline 10 & $50-60$ & Breast & 0 & 4 & LN, CUT & $\mathrm{IHC} 3+$ & 9 & 1 & PD \\
\hline 11 & $60-70$ & Head and neck & 1 & 4 & PUL, PLEU, OS & $\mathrm{IHC} 3+$ & 13 & 1 & PD \\
\hline 12 & $50-60$ & Stomach & 0 & 4 & PERI, OVAR & $\mathrm{IHC} 3+$ & 13 & 1 & PD \\
\hline 13 & $30-40$ & Breast & 0 & 4 & CUT & $\mathrm{IHC} 3+$ & 13 & 1 & PD \\
\hline 14 & $50-60$ & Stomach & 1 & 1 & $\mathrm{LN}$ & $\mathrm{IHC} 2+$ & 13 & 1 & PD \\
\hline
\end{tabular}

The toxicity with this particular dosing schema is favorable. We observed no grade 4 toxicities and an acceptable incidence of grade 3 toxicities (fatigue in six, fever in two, and pain in three of 14 patients). Three patients had to be replaced as they received only two applications. Two of them had rapid tumor progression leading to cancer related death or liver failure. This relatively high replacement rate was mostly attributable to tolerant patient selection criteria as ECOG 2 patients were allowed to be enrolled. In comparison to published results from the previous phase I study with ertumaxomab in metastatic breast cancer [12], our study was associated with less acute toxicities, e.g. fever (all grades $50 \%$ vs. 94 \%). Furthermore, we did not observe any grade 4 ALT/AST (0 \% vs. $42 \%)$. These differences are most likely attributable to the different dosing and escalating schema. The study by Kiewe reported more cytokine release related symptoms, especially at the second and third application of the drug, which is related to the rapid escalation of the antibody dose. This issue is also reflected in the MTD achieved in the mentioned study, which was at $100 \mu \mathrm{g}$ per single dose (in a 10-100$100 \mu \mathrm{g}$ dosing schedule). In our study no DLT was observed in the main dosing cohorts and an MTD was not achieved. The results confirm the tolerability of the new schedule that allows the administrations of higher doses of the antibody. We planned to amend the protocol and further escalate the dose, when the trial withhold due to the unavailability of the study drug. Regarding the immune response to ertumaxomab, we made following observations: CD3 $+\mathrm{T}$ cell counts decreased $24 \mathrm{~h}$ post

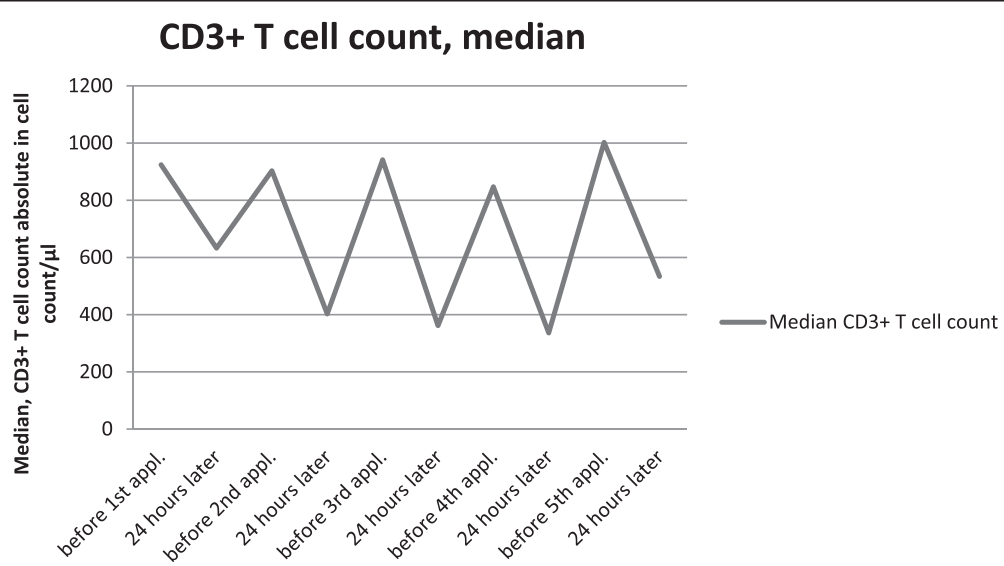

Fig. 3 Median distribution of CD3+ T cells of all patients. Abbreviations: CD, Cluster of differentiation; appl, application 


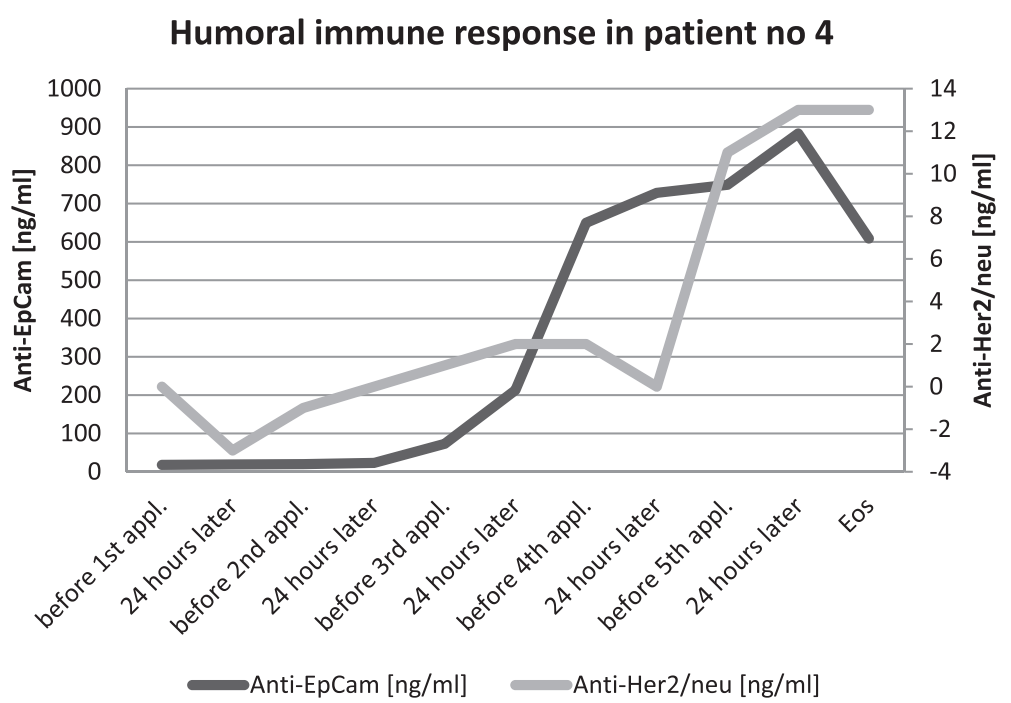

Fig. 4 Humoral immune response against tumor-associated antigens (EpCam and Her2/neu) found in patient \#4. Abbreviations: Appl, application

infusion, but normal values were obtained 1 week later. Transient lymphocytopenia was also observed in other clinical studies with trifunctional antibodies $[12,15]$ and is provoked by their mode of action: The full reversibility and the short recovery period indicate that the phenomenon is attributed to lymphocyte redistribution which could be confirmed in a pre-clinical model [17].

In contrast to the previous published study [12] of ertumaxomab with low incidence of HAMA (25\%) and HARA ( $31 \%$ ), we found HAMA development in eight of nine evaluable patients (89\%) in our study. Most probably, this may be referred to the prolonged dosing schedule used consisting of two cycles with each five applications. However, the induction of HAMA was not dose dependent, nor a correlation with a different toxicity profile was observed. In general, the development of HAMA was not of clinical and practical issue, indicating that a second treatment cycle could be safely administered. Remarkable in this context are results from a phase II/III study with the trifunctional antibody catumaxomab demonstrating a prolonged survival in HAMA positive compared to HAMA negative patients [18].

The monitoring of humoral responses to EpCAM and Her2/neu (in patients without pre-existing humoral immunity) showed increasing antibody titers during treatment in three of five evaluable patients, particular in one patient with corresponding increase in anti-EpCAM and anti-Her2/neu antibodies. Especially the observation of a humoral anti-EpCAM response confirms the potential of the trifunctional antibody to induce a polyclonal anti-tumor response against tumor-associated antigens which are not targeted by the trifunctional antibody itself. Similar immunological activity with increasing humoral and cellular immunity against different tumor-associated antigens was observed with the EpCAM-specific trifunctional antibody catumaxomab applied to gastric cancer patients in the adjuvant setting [19]. These results serve as a further indicator and proof of concept for the "trifunctionality" of ertumaxomab in vivo (with an involvement of antigen presenting cells), leading to immune recognition and priming of a polyclonal humoral immune response against tumorassociated antigens. However, due to the low evaluable patient numbers any conclusion between the induction of humoral immunity and clinical efficacy cannot be drawn.

Regarding the clinical efficacy, we observed two disease stabilizations (one patient with rectal cancer and one with head and neck cancer) and one partial remission (breast cancer) in 11 patients completing 1 cycle and being evaluable for response. The study was designed as a dose finding study. All patients were heavily pretreated, so responses are rarely expected in this patient group.

Although it is known that Her2 positive breast cancer benefits most from anti-Her2 strategies, our results support the evaluation of ertumaxomab in other Her2 positive malignancies as well.

Up to now, several anti Her2/neu strategies are adopted in breast cancer, the prototype disease for Her $2 /$ neu targeted therapy. The most known and most widely used is trastuzumab, a recombinant humanized monoclonal antibody against Her2/neu. Further approved drugs are lapatinib, a dual tyrosine kinase inhibitor of Her1 (also known as EGFR) and Her2/neu, trastuzumab-emtansine, an antibody-drug 
conjugate, consisting of trastuzumab and the cytotoxic agent mertansine (DM1), and pertuzumab, a Her2/ neu dimerization inhibitor. The antibody based strategies are supposed to be functioning not only by blocking the signal transduction but also by an additional immunologic effect. Despite positive results from different phase I studies dealing with anti Her2/ neu vaccination strategies, this concept of potential long lasting tumor control or even a disease eradication could not be established yet [20]. With the novel approach using the trifunctional antibody ertumaxomab different disadvantages and obstacles known from the classical vaccination concept could be overcome, like limitation of immune response to one or few epitopes, HLA restriction, or activation of only one pathway of immune response. Ertumaxomab is supposed to be acting by direct tumor cell/effector interaction and an indirect way by establishing a long lasting immune response.

Taken together, the results of our study have several implications:

First, we could show, that the dosing protocol consisting of two cycles with each five consecutive applications of ertumaxomab (50-100-150-200-300 $\mu \mathrm{g}$ ) was feasible and tolerable. A further dose escalation to higher dose levels, as planned, is currently not possible as the company has to produce a new batch of the investigational drug. It has to be noted, that we could not yet define a MTD with our dosing schema.

Second, in diseases with approved anti Her2/neu drug therapies (breast cancer, gastric cancer), ertumaxomab could expand the therapeutic spectrum, either in (anti Her2) resistant/refractory disease or additionally to established anti Her2 strategies, or even adjuvant concepts.

Third, in Her2/neu overexpressing solid tumors, other than breast and gastric cancer, it could be evaluated as a new personalized treatment approach beyond standard therapy.

In conclusion, the results of our study together with previously published data warrant further evaluation of ertumaxomab in Her2/neu overexpressing solid tumors as a new targeted therapy adding to the armamentarium of personalized cancer treatment.

\section{Conclusion}

In this study we could show that treatment with ertumaxomab in a slow weekly escalating dosing regimen for five consecutive applications (50-100-150-200-300 $\mu \mathrm{g}$ ) is feasible and could confirm the tolerability of the new schedule that allows the administrations of higher doses of the antibody. The results of our study together with previously published data warrant further evaluation of ertumaxomab in Her2/neu overexpressing solid tumors.

\section{Abbreviations}

AE, adverse events; ALT/AST, aspartate aminotransferase/alanine aminotransferase; CRP, C-reactive protein; CTC, common toxicity criteria; DLT, dose limiting toxicity; ECOG, Eastern Cooperative Group; EpCAM, epithelial cell adhesion molecule; Ertu, ertumaxomab; GGT, gamma-glutamyl transpeptidase; HAMAs, human anti-murine antibodies; Her2/neu, human epidermal growth factor receptor 2; $\mathrm{HC}_{\text {, }}$ immunohistochemistry; ISH, in-situ hybridization; LVEF, left ventricular ejection fraction; MTD, maximum tolerated dose; pts, patients; RD, recommended dose; RECIST, response evaluation criteria in solid tumors; SAEs, serious adverse events; SAR, serious adverse reaction; TAA, tumor-associated antigen

\section{Acknowledgment}

No further acknowledgement applicable.

\section{Funding}

This work was supported by a grant of TRION Research GmbH, Martinsried, Germany.

\section{Availability of data and materials}

The dataset supporting the conclusions of this article is included within the main manuscript.

\section{Authors' contribution}

$\mathrm{NH}$ and $\mathrm{AA}$ performed the study treatment, patient management and drafted the manuscript, CP carried out the study coordination and the statistical analysis, KS was involved in patient management, sample preparation and data acquisition, FM was involved in patient management and data acquisition, GMH was involved in patient management and data acquisition, MR was involved in patient management and data acquisition, OGO was involved in patient management and data acquisition, PR carried out the immunological analyses and participated in the data interpretation HL carried out the immunological analyses and participated in the study design and data interpretation, SA designed and coordinated the study, carried out the data interpretation and helped to draft the manuscript. All authors read and approved the final manuscript.

\section{Competing interests}

The authors declare that they have no competing interests. P. Ruf and $\mathrm{H}$. Lindhofer are employees of TRION Research GmbH, Martinsried, Germany.

\section{Consent for publication}

Written informed consent for publication of their anonymized clinical data was obtained from the patients as part of the written informed consent form.

\section{Ethics approval and consent to participate}

The study (EudraCT number: 2011-003201-14; ClinicalTrials.gov identifier: NCT0156941) was conducted according to the principles of the International Conference of Harmonization-Good Clinical Practice and approved by the institutional ethics committee (Ethik-Kommission der Landesärztekammer Hessen). All relevant authorities were notified according to German drug law. All patients signed an informed consent form before participating in the trial.

\section{Author details}

${ }^{1}$ Institute of clinical research (IKF) at Krankenhaus Nordwest, UCT-University Cancer Center, Steinbacher Hohl 2-26, 60488 Frankfurt am Main, Germany. ${ }^{2}$ Department of Hematology and Oncology, Krankenhaus Nordwest, UCT-University Cancer Center, Steinbacher Hohl 2-26, 60488 Frankfurt am Main, Germany. ${ }^{3}$ Department of Medical Oncology, National Center for Tumor Diseases, University Hospital Heidelberg, Im Neuenheimer Feld 460, 69120 Heidelberg, Germany. ${ }^{4}$ Onkologische Schwerpunktpraxis,

Eschollbrücker Str. 26, 64295 Darmstadt, Germany. ${ }^{5}$ Department of Medicine, Hematology and Oncology, Johann Wolfgang Goethe University, Frankfurt, Germany. ${ }^{6}$ TRION Research GmbH, Am Klopferspitz 19, 82152 Martinsried, Germany.

Received: 6 February 2016 Accepted: 27 June 2016

Published online: 07 July 2016 


\section{References}

1. Slamon DJ, Clark GM, Wong SG, Levin WJ, Ullrich A, McGuire WL. Human breast cancer: correlation of relapse and survival with amplification of the HER-2/neu oncogene. Science. 1987;235(4785):177-82.

2. Ross JS, Fletcher JA. The HER-2/neu oncogene in breast cancer: prognostic factor, predictive factor, and target for therapy. Stem Cells. 1998;16(6):413-28.

3. Akiyama T, Sudo C, Ogawara H, Toyoshima K, Yamamoto T. The product of the human c-erbB-2 gene: a 185-kilodalton glycoprotein with tyrosine kinase activity. Science. 1986;232(4758):1644-6.

4. Alroy I, Yarden Y. The ErbB signaling network in embryogenesis and oncogenesis: signal diversification through combinatorial ligand-receptor interactions. FEBS Lett. 1997;410(1):83-6.

5. Prenzel N, Fischer OM, Streit S, Hart S, Ullrich A. The epidermal growth factor receptor family as a central element for cellular signal transduction and diversification. Endocr Relat Cancer. 2001:8(1):11-31.

6. Slamon DJ, Leyland-Jones B, Shak S, Fuchs H, Paton V, Bajamonde A, et al. Use of chemotherapy plus a monoclonal antibody against HER2 for metastatic breast cancer that overexpresses HER2. N Engl J Med. 2001;344(11):783-92.

7. Zeidler R, Reisbach G, Wollenberg B, Lang S, Chaubal S, Schmitt B, Lindhofer $H$. Simultaneous activation of T cells and accessory cells by a new class of intact bispecific antibody results in efficient tumor cell killing. J Immunol. 1999:163(3):1246-52.

8. Lindhofer H, Mocikat R, Steipe B, Thierfelder S. Preferential species-restricted heavy/light chain pairing in rat/mouse quadromas. Implications for a singlestep purification of bispecific antibodies. J Immunol. 1995;155(1):219-25.

9. Zeidler R, Mysliwietz J, Csánady M, Walz A, Ziegler I, Schmitt B, et al. The Fcregion of a new class of intact bispecific antibody mediates activation of accessory cells and NK cells and induces direct phagocytosis of tumour cells. Br J Cancer. 2000;83(2):261-6.

10. Kontermann R, editor. Bispecific Antibodies. Berlin: Springer-Verlag; 2011.

11. Riesenberg $\mathrm{R}$, Buchner A, Pohla $\mathrm{H}$, Lindhofer $\mathrm{H}$. Lysis of prostate carcinoma cells by trifunctional bispecific antibodies (alpha EpCAM $x$ alpha CD3). J Histochem Cytochem. 2001;49(7):911-7.

12. Kiewe $P$, Hasmüller $S$, Kahlert $S$, Heinrigs M, Rack B, Marmé A, et al. Phase trial of the trifunctional anti-HER2 $x$ anti-CD3 antibody ertumaxomab in metastatic breast cancer. Clin Cancer Res. 2006;12(10):3085-91.

13. Eissler N, Ruf P, Mysliwietz J, Lindhofer H, Mocikat R. Trifunctional bispecific antibodies induce tumor-specific $T$ cells and elicit a vaccination effect. Cancer Res. 2012;72(16):3958-66.

14. Ruf $P$, Lindhofer $H$. Induction of a long-lasting antitumor immunity by a trifunctional bispecific antibody. Blood. 2001;98(8):2526-34.

15. Heiss MM, Murawa P, Koralewski P, Kutarska E, Kolesnik OO, Ivanchenko W, Dudnichenko AS, Aleknaviciene B, Razbadauskas A, Gore M, Ganea-Motan E, Ciuleanu T, Wimberger P, Schmittel A, Schmalfeldt B, Burges A, Bokemeyer C, Lindhofer H, Lahr A, Parsons SL. The trifunctional antibody catumaxomab for the treatment of malignant ascites due to epithelial cancer: Results of a prospective randomized phase II/III trial. Int J Cancer. 2010;127(9):2209-21.

16. Jäger $M$, Schoberth $A$, Ruf $P$, Hess J, Lindhofer $H$. The trifunctional antibody ertumaxomab destroys tumor cells that express low levels of human epidermal growth factor receptor 2. Cancer Res. 2009:69(10):4270-6.

17. Dettmar K, Seitz-Merwald I, Lindemann C, Schroeder P, Seimetz D, Atz J. Transient lymphocyte decrease due to adhesion and migration following catumaxomab (anti-EpCAM x anti-CD3) treatment in vivo. Clin Transl Oncol. 2012;14(5):376-81.

18. Ott MG, Marmé F, Moldenhauer $G$, Lindhofer $H$, Hennig M, Spannagl $R$, Essing MM, Linke R, Seimetz D. Humoral response to catumaxomab correlates with clinical outcome: results of the pivotal phase II/III study in patients with malignant ascites. Int J Cancer. 2012;130(9):2195-203.

19. Atanackovic D, Reinhard H, Meyer S, Spöck S, Grob T, Luetkens T, Yousef S, Cao Y, Hildebrandt Y, Templin J, Bartels K, Lajmi N, Stoiber H, Kröger N, Atz J, Seimetz D, Izbicki JR, Bokemeyer C. The trifunctional antibody catumaxomab amplifies and shapes tumor-specific immunity when applied to gastric cancer patients in the adjuvant setting. Hum Vaccin Immunother. 2013:9(12):2533-42.

20. Ladjemi MZ, Jacot W, Chardès T, Pèlegrin A, Navarro-Teulon I. Anti-HER2 vaccines: new prospects for breast cancer therapy. Cancer Immunol Immunother. 2010;59(9):1295-312.

\section{Submit your next manuscript to BioMed Central and we will help you at every step:}

- We accept pre-submission inquiries

- Our selector tool helps you to find the most relevant journal

- We provide round the clock customer support

- Convenient online submission

- Thorough peer review

- Inclusion in PubMed and all major indexing services

- Maximum visibility for your research

Submit your manuscript at www.biomedcentral.com/submit

) Biomed Central 